\title{
Pensamiento crítico y crítica de la economía política'
}

Henry Mora JimÉneZ

RESUMEN: En este trabajo, el autor fundamenta la necesidad de realizar una nueva "crítica de la economía política", en vista de que la economía global imperante convierte a los seres humanos y a la naturaleza en mercancías, lo cual conlleva una amenaza contra la vida.

ASBTRACT: The author of this paper proposes a new criticism on political economy, due to the fact that the ruling global economy turns both human beings and nature into commodities, which implies a threat against life.

\section{Introducción}

a edición argentina de nuestro libro (escrito con Franz Hinkelammert), Hacia una economía para la vida, lleva por subtítulo: "Preludio a una segunda crítica de la economía política". Intentaré aclarar el por qué de este subtítulo, dejando para otra ocasión la respuesta a esta otra interrogante: ¿Por qué una economía para la vida?

Hablar de una segunda crítica de la economía política nos obliga a plantear al menos dos interrogantes: 
1. ¿Por qué una "segunda crítica" de la economía política, si ya otros autores y escuelas de pensamiento han pretendido hacer una crítica de la teoría económica dominante (la denominada economía neoclásica)? Nos referimos, por ejemplo, a Piero Sraffa y a la escuela neo-ricardiana, por un lado; y a la economía ecológica, por el otro. Aunque también podemos mencionar, entre otras, las crí- ticas "realista" (Tony Lawson), institucionalista (Karl Polanyi), culturalista/antropológica (Marshall Sahlins), transdisciplinaria (Max-Neef) y la crítica feminista.

2. Si se trata de una "segunda crítica", cuál fue la primera, y cuál es nuestra relación con ella.

Veamos separadamente ambas interrogantes.

\section{I. ¿Por qué una "segunda crítica” de la economía política?}

\subsection{La crítica de Sraffa}

Comencemos abordando la primera de estas preguntas, recordando que el subtítulo de Producción de mercancías por medio de mercancías, del italiano Piero Sraffa, es precisamente "Preludio a una crítica de la teoría económica". Cercano a Keynes, pero también a Antonio Gramsci y al Partido Comunista Italiano, la crítica de Sraffa a la teoría económica neoclásica, es ante todo, una crítica lógica, es decir, una crítica a la coherencia lógica formal de la teoría neoclásica, especialmente en su versión inglesa (Alfred Marshall). $Y$ aunque muchos de sus análisis son extraordinariamente esclarecedores (el famoso debate sobre la función de producción y la crítica a la teoría neoclásica de la distribución, por ejemplo), no pocos han servido más bien para corregir y depurar la misma teoría neoclásica, convertida hoy en Teoría del
Equilibrio General y Economía del Bienestar.

Lo que Sraffa y los economistas sraffianos no hacen, es una crítica a la coherencia dialéctica de la teoría económica, esto es, una crítica epistemológica y ontológica. Al refugiarse en modelos cada vez más abstractos, la teoría neoclásica ha llegado a un callejón sin salida, la llamada "maldición de Sonnenschein" (el Ilamado Teorema Sonnenschein-Mantel-Debreu), que a grandes rasgos establece lo siguiente: con los supuestos usuales sobre el comportamiento de consumidores y productores, las funciones de demanda y oferta resultantes del modelo de equilibrio general de Arrow y Debreu, pueden asumir cualquier forma, lo que refuta las conclusiones de unicidad y estabilidad del equilibrio general. Esto ha debido ser reconocido por importantes economistas de la misma 
corriente principal y trae a colación la célebre duda de Samuelson:

"Si no pudiera afirmar más que esto - que un equilibrio de oferta y demanda es posible- el economista sería realmente vulnerable a la mofa de que no es más que un loro que ha aprendido a repetir oferta y demanda" (Fundamentos del análisis económico: 265).

Con todo y la importancia de este resultado [las condiciones para el equilibrio no sólo son extremadamente irreales, sino que carecen de significado económico], no logra todavía asentar un golpe definitivo a la teoría neoclásica, aunque la "demostración matemática de la superioridad del liberalismo" (Debreu), si ha quedado claramente en entredicho, incluso al interior del discurso neoclásico.

El problema no es, sin embargo, el equilibrio formal del mercado (equilibrio de ofertas y demandas, o de gastos e ingresos), ya que este se puede lograr cotidianamente en muchos mercados parciales y demostrarse incluso matemáticamente bajo ciertas condiciones no demasiado estrictas, aunque debemos aclarar que más que de un "equilibrio", en este caso deberíamos hablar de una norma de "consistencia formal". El mito de la mano invisible no se constituyó a lo largo de doscientos años para demostrar este equilibrio formal. El mito pretende justificar que un equilibrio formal del mer- cado conlleva, automáticamente, a un equilibrio en las condiciones de la vida real del círculo producciónconsumo; a un equilibrio de lo que Marx denominó, "la vida material de los hombres", a un equilibrio de las necesidades humanas y de la Coordinación del Trabajo Social. Este mito nunca ha sido demostrado y no puede demostrarse. ¡¡Es un mito!!

Si hurgamos en otro tipo de análisis, más propio del "pensamiento crítico" [críticas de la razón utópica y de la razón mítica], no nos podemos conformar con una crítica a la coherencia lógica formal de la teoría económica neoclásica $y$, en especial, a la teoría del equilibrio general. El tipo de análisis que proponemos es el de una crítica a la "coherencia dialéctica" de la teoría y del marco categorial neoclásico. Esta crítica está aún por hacerse, aunque contamos con muchas pistas valiosas y avances parciales.

\subsection{Economía ecológica (Gestión sostenible de los recursos naturales)}

En cuanto a la economía ecológica, esta incorpora un elemento prácticamente ausente en la teoría económica neoclásica inicial: la urgente necesidad de tomar en cuenta los límites biofísicos de la actividad económica, cualquiera que sea la forma social que adquiera el proceso de trabajo social, capitalista, socialista, solidario, etc. 
Se trata sin duda de un aporte central: las economías, y las sociedades, si han de reproducirse y perdurar, tienen que ser "sostenibles".

La teoría económica neoclásica ha sabido responder a una buena parte de esta crítica. Por un lado, ha desarrollado su propia respuesta: la economía ambiental. Por otro lado, ha incorporado a su cinturón protector algunas de estas críticas, como suele hacer con toda la heterodoxia que no cuestione radicalmente el pensamiento neoclásico. El caso más visible y grotesco de esta cooptación es el concepto de "desarrollo sostenible", término hoy en día no solamente engullido y banalizado por la ortodoxia, sino, y lo que más criticable y preocupante, convertido en un "cálculo monetario del límite de lo aguantable": ¿cuánta destrucción, cuánta contaminación, cuánto calentamiento global, cuánto capitalismo aguanta el planeta? Jugamos a saber la respuesta, pero no la sabemos, y no la podemos conocer hasta que el ocurra quiebre definitivo (el Ilamado punto de no retorno). Por eso se impone el llamado principio de precaución, que en el fondo es un valor de respeto de la naturaleza y de reconocimiento a la dignidad de los seres humanos. Ni una, ni otra, pueden ser tratadas como mercancías sin ocasionar procesos destructivos sobre la naturaleza y el ser humano, tal como lo advirtieron claramente Marx y Polanyi.

\section{Hacia una segunda crítica de la economía}

Intentaré ahora responder ahora la segunda de las interrogantes arriba planteada. La segunda crítica que proponemos se monta sobre los hombros de la primera crítica de la economía política, la realizada, fundamentalmente, por Marx. Pero tenemos puntos de encuentro y puntos de desencuentro con Marx que debemos explicitar.

\subsection{Puntos de encuentro}

Partimos de una gran coincidencia: el "humanismo de la praxis" (o humanismo crítico-ético). Este humanismo, no es simple ni fundamentalmente filosófico, y se expresa nítidamente en las dos siguientes afirmaciones del joven Marx:

"La crítica de la religión desemboca en la doctrina de que el hombre es el ser supremo para el hombre y, por consiguiente, en el imperativo categórico de echar por tierra todas las relaciones en que el hombre sea un ser humillado, sojuzgado, abandonado y despreciable" (La sagrada familia, incluido en Fromm, Marx y su Concepto del Hombre, Vigésima reimpresión, FCE, 2009: 230). 
"El defecto fundamental de todo el materialismo anterior -incluido el de Feuerbach - es que sólo concibe las cosas, la realidad, la sensoriedad, bajo la forma de objeto o de contemplación, pero no como actividad sensorial humana, no como práctica, no de un modo subjetivo [...] Por tanto, no comprende la importancia de la actuación revolucionaria". (Tesis sobre Feuerbach. En C. Marx y F. Engels, Obras escogidas, Editorial Progreso, Moscú, 1976:7).

Así, el punto de partida de la crítica no son los valores de por sí, ni la enajenación de por sí, ni la propiedad privada de por sí, sino el ser humano concreto y la reproducción material de su vida. En esto coincidimos totalmente.
Nuestra otra gran coincidencia con la primera crítica de la economía política es, precisamente, su crítica del capitalismo, crítica que consideramos esencialmente correcta y que se resume en esta cita de El Capital:

\begin{abstract}
"Por tanto, la producción capitalista sólo sabe desarrollar la técnica y la combinación del proceso social de producción socavando al mismo tiempo las dos fuentes originales de toda riqueza: la tierra y el hombre" [hombre en cuanto trabajador, sujeto productor]. (Marx, El capital, FCE, T. I, 1973: 424)
\end{abstract}

Estas dos grandes coincidencias son suficientes para aclarar lo que queremos decir con la expresión "nos montamos sobre los hombros de la primera crítica de la economía política". Hay otras, pero no hay tiempo para exponerlas (la teoría del valor, la teoría del fetichismo, las principales leyes de tendencia del capitalismo, etc.).
Partiendo de estas dos coincidencias es posible efectuar la crítica a la economía burguesa actual para demostrar la negación de lo humano, tal como aparece en este pensamiento y en la práctica del capitalismo. Veámoslo a partir de una cita clave de Adam Smith:

"En una sociedad civil, solo entre las gentes de inferior clase del pueblo puede la escasez de alimentos poner límite a la multiplicación de la especie humana, y esto no puede verificarse de otro modo que destruyendo aquella escasez una gran parte de los hijos que producen sus fecundos matrimonios. [... ] Así es como la escasez de hombres, al modo de las mercaderías, regula necesariamente la produc- 
ción de la especie humana: la aviva cuando va lenta y la contiene cuando se aviva demasiado. Esta misma demanda de hombres, o solicitud o busca de manos trabajadoras que hacen falta para el trabajo, es la que regula y determina el estado de propagación, en el orden civil, en todos los países del mundo" (Adam Smith, La riqueza de las naciones. Universidad Autónoma de Centroamérica, San José, Costa Rica, 3 tomos, 1986: 124)

Es un texto impactante, y hasta brutal, pero tiene la ventaja de reconocer que existe un "circuito natural de la vida humana", aunque no se lo acepte como criterio de racionalidad. Todo lo contrario, es el mercado el que actúa aquí como criterio de racionalidad y éste se impone sobre el circuito natural de la vida humana, determinando quienes viven y quienes no viven. La prosperidad ("el estado de propagación") se basa en el sacrificio de los sobrantes (mecanismo de regulación de la escasez de hombres), siempre que esto sea necesario. Es un texto cínico, pero no hipócrita (a diferencia de muchos textos modernos).

En este pasaje del liberalismo clásico, el laissez faire, laissez passer se transforma en laissez faire, laissez mourir. Dejar morir por enfermedades prevenibles y curables, dejar morir en la miseria o en la exclusión; morir sepultado a cientos de metros bajo el suelo en una mina de carbón, morir de frío en la acera de un barrio pobre de cualquier ciudad septentrional, etc.; quizás no es matar directa y premeditadamente. La ley no permite matar, pero permite dejar morir y llevar a las personas (y a la naturaleza) a situaciones en las cuales, aunque lentamente o accidentalmente, están condenadas a morir.

Para Adam Smith, es el sacrificio necesario de los sobrantes. Para la actual estrategia de acumulación de capital a escala mundial (Ilamada globalización), son las "víctimas de la libertad", porque la ley instrumentalizada por la maximización de la ganancia es considerada ley de la libertad. Y la libertad (el mercado) tiene que ofrecer sacrificios humanos para poder asegurar — supuestamente_- el bien de todos.

Marx cambia radicalmente este punto de vista, y lo hace en dos sentidos claramente explícitos.

En primer lugar, sustituye la reproducción "de los factores" por la reproducción del ser humano y, por tanto y necesariamente, de la naturaleza proveedora de los valores de uso ("las dos fuentes originarias de toda riqueza").

Y en segundo lugar, el mercado no es ya el criterio de racionalidad sobre la vida, sino al contrario, la 
reproducción de la vida real es el criterio con el que debe evaluarse al mercado y a cualquier otra relación social institucionalizada.

Como corolario, la "reproducción material de la vida humana" aparece como última instancia de todas las decisiones económicas y políticas, siendo la reproducción de "los factores" una consecuencia de la reproducción material de la vida humana. Y estos son los nuevos puntos de partida que permiten a Marx "poner de pie lo que antes estaba de cabeza".

\subsection{Nuestros desencuentros con Marx... y nuestro acercamiento al Buen Vivir}

Pero veamos ahora algunos puntos de desencuentro con Marx.

El primero no es en realidad una diferencia: Marx hace su crítica a partir de la economía política de su tiempo, tanto de aquella que denominó "economía vulgar", como a la que catalogó "economía política burguesa científica" (Smith, Ricardo).

La segunda crítica de la economía política tiene que hacerse a la teoría económica de nuestro tiempo, es decir, a la teoría económica neoclásica, ortodoxa, dominante. $Y$ aquí si tenemos que señalar una diferencia importante con la tradición marxista: esta tiende a considerar la teoría económica neoclásica como la heredera de la economía vulgar pre-neoclásica, con una función fundamentalmente apologética. Nosotros creemos que la economía neoclásica, sin dejar de cumplir esta función apologética que le es propia, incorpora elementos centrales para una ciencia de lo económico a los que necesariamente hay que dar respuesta, como es, sin duda, el problema de la asignación de los recursos escasos y todo su desarroIlo matemático operativo; así como, a sus nociones de eficiencia y de racionalidad. Igualmente, hay que criticar, y no simplemente ignorar o desechar, toda la tradición de construir modelos o "conceptos límite" trascendentalmente no factibles, (competencia perfecta, equilibrio general competitivo, planificación perfecta); pero que aun así juegan un papel muy importante en la crítica por realizar; pues representan el marco categorial y el horizonte utópico de esta teoría.

Una diferencia importante con Marx que sí hemos de resaltar es su crítica abolicionista del mercado.

Aunque nuestra crítica al mercado es radical, y sostenemos que, efectivamente, el mercado contiene intrínsecas tendencias autodestructivas y destructivas de la vida, tendencias que el mercado descontrolado hace efectivas (crisis recurrentes, concentración de la riqueza, pauperización, desarrollo desigual, expoliación y destrucción de la naturaleza); la idea de la abo- 
lición del mercado, o del mercado reducido a su mínima expresión, y por tanto, el mercado como "un mal necesario", es, además de incorrecta, trascendentalmente no factible (igualmente incorrecta es la tesis paralela de la abolición del Estado).

Nuestra respuesta recupera la vieja discusión (soviética de los años 30 y cubana de los años 60 del siglo pasado) sobre, "el control consciente de la ley del valor", pero la actualizamos en función de una "intervención sistemática de los mercados".

Esta intervención sistemática de los mercados no es una intervención en el sentido keynesiano o institucionalista. Hoy en día hasta el Banco Mundial acepta que el mercado necesita de instituciones y regulaciones que lo complementen.

La intervención keynesiana de los mercados y otras similares, es una intervención en función del mercado mismo y de su supuesta eficiencia, por lo que sigue siendo mercado-céntrica.

Por el contrario, la "intervención sistemática de los mercados" que proponemos, es una intervención a partir del criterio de la reproducción de la vida humana. Por tanto, puede plantearse desde simples regulaciones laborales y ambientales en el caso de la pro- ducción de hortalizas, pasando por endurecer estas y agregar limitaciones territoriales y ecológicas en el caso de la producción de banano o piña, hasta regulaciones que conlleven a la minimización y hasta la suspensión del mercado como mecanismo de coordinación en áreas como la salud, la educación, la energía, el agua o la ingeniería genética. Y la interpelación del mercado no debe proceder sólo del Estado (Estado Social), sino también de la sociedad civil y de las prácticas o intervenciones sociales (economía social y solidaria).

Y aquí establecemos un fuerte vínculo con el paradigma comunitario del Buen vivir que florece en toda América Latina, al hacernos la siguiente pregunta: ¿cuál es el sentido de la vida? Y nuestra respuesta es: ¡El sentido de la vida es vivirla!

Lo primero en la vida del ser humano, no es la filosofía, no es la ciencia, no es el alma, no es la sabiduría, no es la búsqueda de la felicidad, no es el placer, no es la reflexión sobre Dios; es, la vida misma. Toda libertad, toda filosofía, toda acción, toda relación con Dios, presupone el estar vivos. Presupone por tanto, la posibilidad de la vida, de la vida material, concreta, corpórea. Y esta posibilidad de la vida presupone el acceso a los medios para poder vivir:

Me quitan la vida al quitarme los medios que me permiten vivir.

(W. Shakespeare). 
No es la pregunta de si existo o no (Descartes), como pregunta clave, sino la pregunta, de si puedo seguir existiendo. No es la pregunta de si la vida es un sueño (Calderón de la Barca), sino la pregunta por las condiciones de posibilidad de vivir como ser viviente.

Pero entonces, insistimos: ¿La vida vale o no vale la pena vivirla?

La pregunta no es trivial, o al menos, ya no lo es. En nuestra sociedad actual está reapareciendo una cultura del heroísmo del suicidio colectivo, una cultura de la desesperanza que se basa en la tesis de que no hay alternativa frente a las amenazas globales que hoy socavan los cimientos mismos de la sociedad mundial y al mismo equilibrio planetario ("sistema Tierra" o "sistema Tierra-Luna"): la desigualdad y la exclusión social crecientes, las crisis ecológicas y las crisis de las relaciones humanas.

Estas crisis amenazan la vida, y están íntimamente relacionadas con la negación del sujeto humano en cuanto sujeto corporal, viviente, y son el producto de una sacralización de las relaciones sociales de producción, sacralización que apareció tanto en la ideología estaliniana (en la antigua Unión Soviética), como actualmente en la ideología neoliberal; aunque hoy por hoy, el mito del progreso técnico infinito y la negación y aplastamiento de cualquier alternativa, asume la forma de una política de totalización del mercado; por eso nuestro énfasis en su crítica.

El problema, creemos, no es el mercado, sino la pretensión teórica y el proyecto político de totalizar el mercado. La realización de semejante proyecto destruiría a la humanidad.

Por eso, frente al mercado, necesitamos una pluralidad de formas de propiedad.

Como se sostiene en La vida o el capital, de Duchrow y Hinkelammert:

"El socialismo histórico encaró la cuestión de la propiedad en un sentido principalista, de manera similar a lo que hace la sociedad capitalista [. ... ] la sociedad capitalista ve la propiedad privada como la llave para la solución de todos los problemas, sin discutir siquiera el hecho de que la solución de problemas diversos exige también formas de propiedad diversas; [... ] el socialismo histórico hizo algo análogo, aunque a la inversa.

Tenemos que liberarnos de estos principalismos para determinar con libertad las modalidades de propiedad más 
adecuadas a los problemas específicos que debemos solucionar" (Ulrich Duchrow y Franz Hinkelammert, La vida o el Capital. Alternativas a la dictadura global de la propiedad. DEI, 2003: 14).

Por tanto, estas opciones alternativas al mercado y a la propiedad, sea privada o estatal, no son solamente opciones para los pobres y excluidos, aunque desde luego, la exclusión, la pobreza y el desempleo son indicadores de irracionalidad de un sistema incapaz de incluir a toda la sociedad en el sistema de la división del trabajo social. Pero también son opciones necesarias frente a la totalización del mercado, teniendo presente que todas y todos debemos estar incluidos, no necesariamente en el circuito del mercado, pero sí, en el sistema de división del trabajo social y en el circuito natural de la vida humana.
La tercera y última diferencia que quiero resaltar, con respecto a los resultados de la primera crítica de la economía política es de carácter más radical.

Marx se da cuenta de que la propiedad privada no es la causa última de las relaciones de dominación, de las clases, de la explotación y del Estado.

Cree encontrar esta causa última en una forma particular de la división del trabajo, y su crítica de fondo se refiere a una cierta división del trabajo:

"En efecto, a partir del momento en que comienza a dividirse el trabajo, cada cual se mueve en un determinado círculo exclusivo de actividades, que le viene impuesto y del que no puede salir; el hombre es cazador, pescador, pastor o crítico y no tiene más remedio que seguir siéndolo, si no quiere verse privado de los medios de vida; mientras que en la sociedad comunista, donde cada individuo no tiene acotado un círculo exclusivo de actividades, sino que puede desarrollar sus aptitudes en la rama que mejor le parezca, la sociedad se encarga de regular la producción general, con lo que hace cabalmente posible que yo pueda dedicarme hoy a esto y mañana a aquello; que pueda por la mañana cazar, por la tarde pescar y por la noche apacentar el ganado, y después de comer, si me place, dedicarme a criticar, sin necesidad de ser exclusivamente cazador, pescador, pastor o crítico, según los casos... 
Y precisamente por esta contradicción entre el interés común, cobra el interés común, en cuanto Estado, una forma propia e independiente, separada de los reales intereses particulares y colectivos $y$, al mismo tiempo, como una comunidad ilusoria, pero siempre sobre la base real de los vínculos existentes, dentro de cada conglomerado familiar y tribal, tales como la carne y la sangre, la lengua, la división del trabajo en mayor escala y otros intereses; y sobre todo, como más tarde lo desarrollaremos, sobre la base de las clases, ya condicionadas por la división del trabajo, que se forman y diferencian en cada uno de estos conglomerados humanos y entre las cuales siempre hay una que domina sobre todas las demás" (La ideología alemana, incluido en Fromm, op. cit., p. 215).

El problema no es en sí la división del trabajo, sino esta división del trabajo que Marx Ilama "natural", y que quizás sería preferible denominar, "coactiva", por oposición a "voluntaria" [inicia como "natural" para luego transformarse en "coactiva"]. Se trata de una visión radicalmente antiinstitucional de relaciones directas entre los seres humanos, sin ningún tipo de institucionalización. Es el "orden espontáneo" de las relaciones humana directas.

Pero en El capital Marx usa un concepto paralelo a este "concepto límite" del hombre total y de la sociedad total y definitivamente liberada, y se acerca a una idea que después se asentó definitivamente en el marxismo institucionalizado: la idea de una institución sin los efectos enajenantes de la institucionalización y de una división del trabajo sin los efectos distorsionantes de la división del trabajo. Es el caso, por ejemplo, de su referencia a la empresa capitalista como una división del trabajo a priori, mientras que el mercado capitalista tiene una división del trabajo a posteriori. Marx habla de la nueva sociedad como una aplicación a toda la sociedad de esta división del trabajo a priori ya existente dentro de la empresa capitalista. El "plan social".

Sin duda, este fue el camino que intentó seguir el socialismo soviético: la instauración de una división del trabajo a priori a través de la planificación, en supuesta sustitución de la división del trabajo a posteriori del mercado.

Ahora bien, la experiencia soviética ha demostrado que ni la división del trabajo voluntaria, ni la división del trabajo a priori, son trascendentalmente realizables, a no ser como aproximaciones, y aun así, no como aproximaciones asintóticas calculadas, sino solamente como referentes utópicos.

La respuesta de Marx frente a este doble desdoblamiento de la división del trabajo social (voluntaria/ coactiva, a priori/a posteriori) es, la 
revolución total, el hombre total, esto es, totalmente humano, emancipado, liberado. La sociedad sin clases y sin Estado, sin propiedad privada y sin mercado. La "regulación comunista de la producción".

Pero las condiciones para una tal "planificación perfecta" de la división del trabajo social son tan extravagantes e irreales como lo son las condiciones para una "competencia perfecta" en la teoría neoclásica. Ambos son conceptos límite, trascendentalmente no factibles.

Hay que buscar otra salida. $Y$ en eso están ustedes, el pueblo salvadoreño, y también, muchos otros pueblos de América Latina.

\section{Gobernar obedeciendo y derechos concretos a la vida}

Y aquí nuevamente vemos puentes y avenidas de diálogo y el Buen Vivir.

La clave de esta toma de consciencia es el concepto de no factibilidad trascendental del orden espontáneo (anarquismo, planificación perfecta, competencia perfecta, equilibrio general competitivo, regulación comunista de la producción), lo que nos lleva a plantear el problema de la emancipación humana en los términos de la obstinada presencia de una institucionalidad que es negatividad de la vida humana, pero sin la cual la vida humana tampoco sería posible.

Es una dialéctica maldita con la cual tenemos que convivir, pero que no por ello debemos aceptar.

Frente a su obstinada presencia, hay una "ausencia presente" que es el grito del sujeto que se resiste a ser tratado como un ser humillado, sojuzgado, abandonado y despreciado.
Enfrentamos por tanto esta paradoja: Una sociedad no puede no institucionalizarse, pero la sociedad sin clases no puede institucionalizarse. Dentro de estos términos, el control por la soberanía popular y ciudadana de las clases dominantes, de la institucionalidad misma y de las ideologías resultantes, sí es factible. Es el "gobernar obedeciendo".

La sociedad sin clases, por lo tanto, ya no se puede concebir en el sentido original del concepto límite. Hay que concebirla necesariamente como una sociedad en la cual esta tendencia continua a la formación de una clase dominante es continuamente contrarrestada. Es sociedad sin clases solo en el grado en que logra convertir el poder económico y con ello el poder político, en articulación de la soberanía popular. No por eso desaparece como poder, pero surge como poder controlado, limitado y cada vez más instrumentalizado en función de una democracia real articulada por la soberanía popular. 
"Gobernar obedeciendo es afirmar cada día que el soberano no es el Estado, que el soberano es el pueblo, que no se manifiesta cada cinco años con el voto, sino que se manifiesta, habla, propone cada día necesidades, expectativas y requerimientos colectivos.

Lo que se le pide al gobernante es sintetizar y unir, porque pueden haber voces discordantes dentro del pueblo. El pueblo no es una cosa homogénea, ino señores!, hay clases sociales, hay identidades, hay regiones. El pueblo es muy diverso.

El trabajo del gobernante no es sustituir al pueblo, es armonizar las voces del pueblo, sintetizar en un sólo sentido sus inquietudes. Pero eso no significa que el gobernante sustituya al pueblo.

Gobernar obedeciendo es eso: el soberano es el pueblo y el gobernante es simplemente un unificador de ideas, un articulador de necesidades, y nada más". [Palabras finales pronunciadas por el vicepresidente de Bolivia, Álvaro García Linera, en Conferencia de Prensa el 28 de noviembre del 2011 en Maracaibo, Venezuela, en el marco del VI Foro Internacional de Filosofía (Transcripción de Marta Harnecker). Publicadas en Rebelion.org el 27 del 01 del 2012.]

Es la nueva sociedad basada en el derecho de todos/as a la vida, en cuanto que anticipación de la "Nueva Tierra", del "Buen vivir", que siempre será el trasfondo de la esperanza. Se trata de cuatro derechos esenciales:

1. Frente a la exclusión y precarización del trabajo resultante de la actual estrategia del capital, (la globalización del neoliberalismo), la base de todos los derechos concretos a la vida es el derecho a un trabajo digno y seguro, desde donde se derivan los siguientes derechos concretos a la vida.

2. La satisfacción de las necesidades humanas básicas. Además del derecho al trabajo, se trata de la salud, la educación, la seguridad ciudadana y la vivienda, en el marco de las posibilidades del producto social. Estos se refieren a los elementos materiales necesarios para lograr la satisfacción de las necesidades humanas corporales básicas en toda su amplitud, incluyendo las necesidades culturales y espirituales. 
3. La participación democrática de las ciudadanas y los ciudadanos en la vida social y política, así como su realización personal y social en el marco de un sistema de propiedad que asegure el empleo y la distribución adecuada de los ingresos y el cumplimiento de las legítimas aspiraciones sociales.

4. Un determinado orden de la vida económica y social, en el que sea posible conservar y sostener el medio ambiente como base natural de toda la vida humana.

Estos derechos fundamentales son, al mismo tiempo, derechos económicos y sociales, y determinan el marco del orden social. Se trata de construir permanentemente un orden social que no destruya las condiciones de la existencia material de ese mismo orden, sin las cuales no sobreviviría ningún orden social. Estos derechos concretos a la vida determinan el marco de vigencia de todos los derechos humanos en su conjunto. No obstante debemos agregar tres más que son derechos políticos hoy estrictamente necesarios para alcanzar una democracia real en América Latina. Estos son:

5. El derecho político a la intervención en los mercados y, por tanto, en el poder de las burocracias privadas transnacionales. No se trata de revivir una planificación centralizada, pero sí una planificación global y un direccionamiento de la economía en su conjunto.

6. La recuperación de la libertad de opinión (hoy sofocada en nombre de la libertad de prensa) $y$,

7. La libertad de elecciones (hoy secuestrada por las burocracias privadas que se han convertido en financistas de los candidatos por elegir).

Hoy no es posible recuperar la democracia y el ejercicio de la soberanía popular sin recuperar el derecho fundamental a la intervención sistemática en los mercados. Se trata de la base de toda democracia económica y social factible, y sin ella las instituciones democráticas son transformadas en simple pantalla de un poder absoluto ajeno a todo control democrático.

En estos términos -creemos- sería posible volver a pensar en una república libre, que hoy tiene una nueva forma de utopía: una sociedad en la cual quepamos todos/as, naturaleza incluida; reproduciendo la riqueza que sustenta la vida humana sin socavar las dos fuentes originarias de esta riqueza: el ser humano y la naturaleza. Incluye asimismo un proyecto democrático, porque no le corresponde una estrategia única, sin alternativas, sino estrategias múltiples, donde otras economías y otros mundos sean posibles. 
NotA

1 Texto de la ponencia leída el 15 de marzo de 2012 en la Universidad de El Salvador, en el contexto de las Jornadas Interuniversitarias de Economía crítica, organizadas por las UCA, la UES y la ULS, del 14 al 17 de marzo del corriente año. 